\title{
Integrating eye health into policy: Evidence for health systems strengthening in KwaZulu-Natal
}

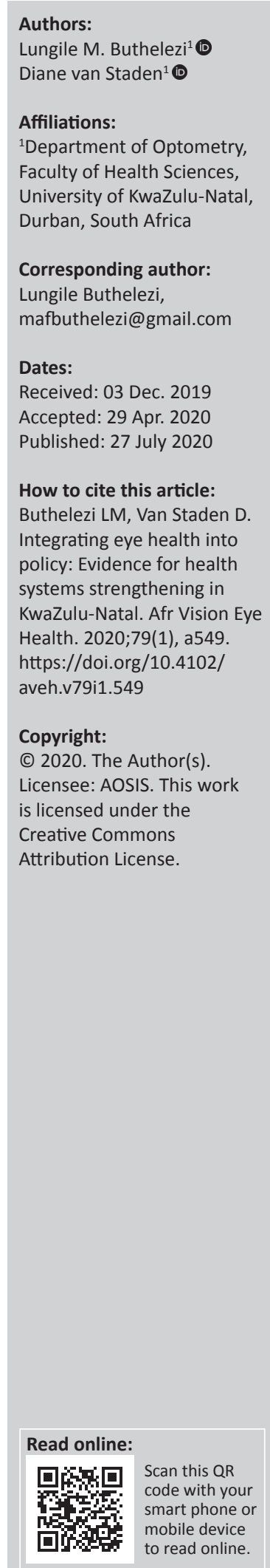

Background: Available evidence is that eye health care receives less attention compared to other allied health professions in public health services across South Africa, yet vision impairment is known to have significant social and economic consequences. Rural areas appear to be more affected, with KwaZulu-Natal (KZN) representing the second-most populous province in the country. The World Health Organization formulated a health systems framework which describes health systems in terms of six building blocks. This approach was applied in KZN, to assess the Department of Health's capacity to provide comprehensive primary eye health services in KZN, South Africa.

Aim: To determine the capacity for comprehensive primary eye care service delivery within the public health sector in KZN.

Setting: All health disctrict in KwaZulu-Natal.

Methods: An explorative-descriptive cross-sectional design, gathering both quantitative and qualitative data, was used. Data were collected utilising questionnaires, observation, and interviews. Results were analysed against the health systems framework.

Results: A total of 28 optometrists responded to the survey, representing $60 \%$ of public health facilities that provide eye health care in KZN. The majority $(53.6 \%)$ of optometrists were from district hospitals in rural areas. Facilities were generally inadequately equipped, with inefficiencies in service delivery including long waiting times and multi-tasking of clinicians. The absence of a financing model impacted the service at all levels.

Conclusion: Policy development for eye health is necessary for KZN to deliver comprehensive eye health services. In particular, emphasis should be placed on the integration of eye health into primary health care and appropriate planning to foster accessibility and sustainability of services.

Keywords: eye health; health systems; optometry; primary healthcare; public health.

\section{Introduction}

The first-ever 'World Report on Vision' states that currently, there are an estimated 2.2 billion people globally who suffer from vision impairment (VI). ${ }^{1}$ Of these, at least 1 billion have VI that could have been prevented or is yet to be addressed. Avoidable causes of VI and blindness include refractive error (123.7 million), cataract (65.2 million), glaucoma (6.9 million), diabetic retinopathy ( 3 million), and trachoma ( 2 million). ${ }^{2,3}$ South Asia and sub-Saharan Africa have the highest blindness statistics amongst adults over the age of 50 with each of these regions accounting for $4.0 \%$ and $9.4 \%$ of the total global blindness respectively. Whilst a decline in the global burden of blindness was observed until 2015, recent estimates are that the number of blind people in the world will triple by 2050 due to global population growth forecasts. ${ }^{2}$ Bourne et al. ${ }^{2}$ further reported that the ageing global population will give rise to a $35 \%$ increase in blindness and VI numbers. This will negatively impact health systems which already face high disease burdens and are under-resourced.

Uncorrected refractive error is the leading cause of VI worldwide, ${ }^{2}$ with the greatest burden being in rural areas of low-resource countries. ${ }^{3}$ VI and age-related eye diseases affect economic and educational opportunities, and reduce the quality of life of affected individuals. ${ }^{4}$ This is principally due to a lack of access to eye health services, which inevitably contributes to unnecessary causes of blindness and VI. ${ }^{5}$

There are 890 million inhabitants in 47 countries in Africa who are considered member states of the World Health Organization (WHO). ${ }^{6}$ The prevalence of VI in Africa is estimated to be 26 million, of whom almost 6 million are blind. The burden of eye disease in sub-Saharan Africa 
is currently estimated to affect $18 \%-25 \%$ of this population. ${ }^{1}$ Whilst Africa has amongst the highest prevalence of blindness globally, it is the most underserved continent concerning human resource (HR) availability to meet the eye health needs of populations. ${ }^{6}$

Statistics South Africa ${ }^{7}$ estimated the population of this country to be 57.73 million in 2017 and found that vision impairment was the highest form of disability in the country. Furthermore, approximately $9.2 \%$ of the total population used spectacles as a form of vision corrective device. The survey further concluded that KwaZulu-Natal (KZN) had the second-highest seeing disabilities surveyed in 2017.

According to the 2002 data, by the National Department of Health (NDoH), the prevalence of blindness in South Africa is estimated to be $0.75 \%{ }^{8}$ The majority $(80 \%)$ of those are classified as having avoidable blindness and living in rural areas. There has been no evidence of recent blindness statistics conducted by the Department of Health $(\mathrm{DoH})$ since that year. A study by Naidoo et al. ${ }^{9}$ however, found that the prevalence of blindness in South Africa is $0.9 \%$ and that the leading causes are cataract, refractive error and glaucoma, which are all preventable causes of VI. There has not been any comprehensive population-based survey on blindness and VI conducted in KZN. ${ }^{9}$ Govender et al. ${ }^{10}$ found that in the eThekwini metropole, the leading cause of blindness and severe VI was cataract, followed by uncorrected refractive error.

The WHO Global Action Plan for the Prevention of Avoidable Blindness and Visual Impairment recognises that the provision of effective and accessible eye care services is central to controlling VI and blindness. It further promotes the integration of comprehensive eye care services into Primary Health Care (PHC) as part of health systems strengthening. ${ }^{11}$ Access to comprehensive eye health services is therefore aligned to the principle of universal health coverage as adopted by the WHO. ${ }^{11}$

The health system in South Africa consists of both public and private sectors. ${ }^{12}$ The public health sector serves the majority of the population and is based on a district health system model which incorporates a network of primary health care facilities that deliver integrated health services to defined populations. ${ }^{12}$ Eye care in South Africa is largely provided at a PHC level, referred to as primary eye care, ${ }^{13}$ with PHC facilities referring complex cases to higher levels of care when there is a need for this. ${ }^{13}$

Whilst South Africa's policy on health has the district health system as a cornerstone, various services, especially eye care, have been poorly defined. ${ }^{14}$ It was noted by Cook, Knight, and Crofton-Briggs ${ }^{15}$ that the coordination between the different levels of the eye health system is inadequate due to poor communication and a complex referral system. A comprehensive eye health system presumes the availability of relevant supporting policy and resource provision, necessary equipment for testing and efficient systems for eye health care. ${ }^{16}$ In the last decade, various studies ${ }^{1,2}$ have reported on the global magnitude of VI, most referring particularly to refractive error, cataract, and glaucoma. These studies are considered to be epidemiological in nature and provide an insight which supports advocacy calls for improved planning of eye health services. ${ }^{17}$ However, very few studies investigated eye health services from a systems perspective, with one study recently looking at PHC services in three districts in South Africa. ${ }^{13}$

As an acknowledgement of the health systems strengthening agenda, the WHO formulated a framework (Figure 1) that describes health systems in terms of six building blocks. ${ }^{18}$

This study assessed the eye health system in KZN from the perspective of optometrists as primary eye care providers, and eye care service managers responsible for planning, against the health systems building blocks. The objective was to determine if the KZN DoH can deliver comprehensive eye health services to the province's population. This research considered comprehensive healthcare from a primary eye health care delivery and health systems strengthening perspective using the WHO health system framework.

\section{Research methods and design}

This explorative-descriptive mixed methods research project followed a cross-sectional study design. Mixed methods take advantage of the strengths of both quantitative and qualitative methods. ${ }^{19}$ Quantitative techniques describe a phenomenon, explain relationships and differences amongst variables. Whereas qualitative research aims to understand phenomena with more depth and people's subjective experiences in their social situations. ${ }^{20}$

\section{Study setting}

The KZN population is estimated to total 11.3 million, making up $19.9 \%$ of the nation's population ${ }^{21}$ and where $84 \%$ of the population is dependent on public health services. ${ }^{22}$

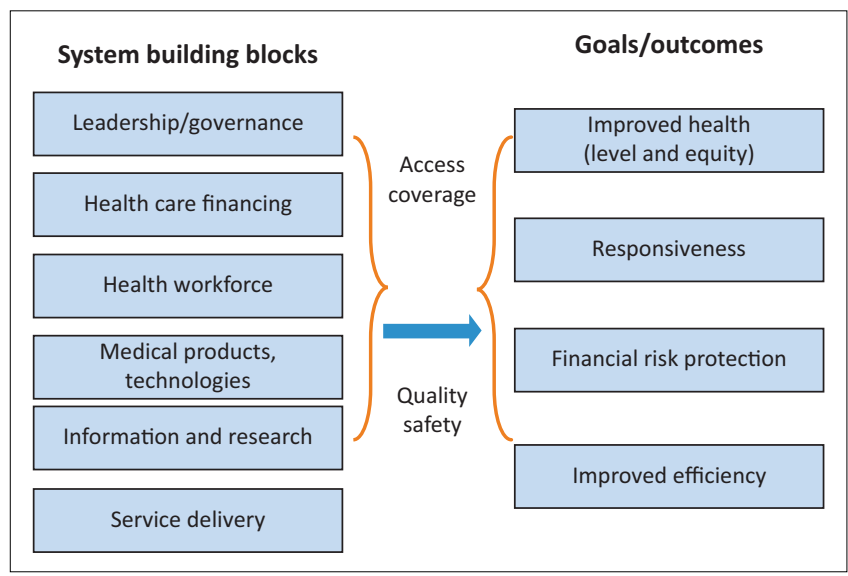

Source: The World Health Report 2000: Health systems: Improving performance. Public Health Report. 2001;116:268-289.

FIGURE 1: World Health Organization health system building blocks. ${ }^{18}$ 
The province is divided into 44 local municipalities, 1 metropole and 10 health districts. ${ }^{21}$

\section{Sampling frame}

For the questionnaire, a purposive total population sampling technique was adopted which includes the entire population who share common characteristics. ${ }^{23}$ In this study, the total population consisted of 56 optometrists who were working in the KZN public health sector, of which all were invited to participate in the study.

Public health care facilities were also selected using a purposive total population sampling technique. Invitation to participate was sent to the entire population made up of 41 public health facilities which provided eye health care in KZN.

A purposive expert sampling, which only includes those with knowledge ${ }^{23}$ in a certain area, was adopted. For this study, five key informants were used, who were KZN DoH district health co-ordinators and hospital managers, and who were involved in decision making in eye health care.

\section{Data collection}

All data were collected by the researcher in a concurrent (QUAL + QUAN) approach between February and June 2019 using questionnaires, observation and key informant interviews.

An Eye Health Systems Assessment (EHSA) developed by the International Centre for Eye Health helps determine how eye care can fit into broader health systems. ${ }^{18}$ It assists in assessing the strengths and weaknesses of these health systems and identifying strategies for policy and planning in eye health system strengthening. Questions for this project's questionnaire were guided by this tool ${ }^{18}$ and adapted for the KZN context.

The questionnaire sought to elicit information about the number of optometrists, their demographics, and distribution within the province. It also investigated the services delivered by the optometrists, and the equipment available to them. Questionnaire participants were invited via email, social media and in the form of a QR code sent to participants for self-completion after informed consent was granted. Optometrists were selected for this aspect of the study as they are considered primary eye health care practitioners who are trained to provide comprehensive eye and vision care and to address uncorrected refractive error as a significant cause of VI. ${ }^{24}$

For the structured observation, the researcher observed 15 hospitals in various districts of KZN to audit available equipment for comprehensive eye health service delivery using the minimum requirements as stated by the Health Professionals Council of South Africa ${ }^{25}$ and the International
Agency for the Prevention of Blindness' Vision 2020 requirements. ${ }^{26}$ General observations relating to eye health service delivery were recorded using an unstructured observation tool. Optometrists in the facilities were invited to participate via email and telephonic communication with resident optometrists.

For the interviews, five key informants were purposively selected based on their involvement in, or knowledge about the eye health service in KZN's public sector. The interviews sought to investigate perceptions and experiences relating to service delivery and planning, as well as general opinions on the ability of the KZN DoH to deliver comprehensive eye care services to the KZN population. The key informants were from both urban and rural areas occupying positions within the $\mathrm{DoH}$ and public sector eye care facilities. Interviews were conducted in English and audio recorded. All audio recordings were backed up onto Cloud Storage from Google Drive. The transcripts were coded to ensure confidentiality of participants. There were no other individuals present during the interview process of all interviewees.

\section{Data analysis}

Both descriptive and inductive approaches were employed for parallel mixed analysis. The quantitative and qualitative data analysis occurred separately, neither type of analysis affected the other, and the results from each analysis were combined once both sets of data analyses were complete. Quantitative data from the questionnaire were analysed by a statistician to calculate: confidence intervals (CI) (level of confidence $=95 \%$ ), effect sizes for practical significance [Phi and Cramer's $V=$ small (0.2), medium (0.5), and large $(0.8)]$ and chi-square to determine $p$-values for statistical significance $(p \leq 0.05)$. Descriptive quantitative analysis was utilised to analyse the variation between hospitals from the facility checklist. Qualitative content analysis was done through coding of the transcribed interview texts. The coding aimed to discover emergent themes to identify underlying meanings in the text.

The triangulation methodology strategy selected minimised bias, attained data saturation, and tested the validity of data through the convergence of information from different sources of data collection adopted.

The building blocks were analysed based on equity, efficiency, access, quality and sustainability of the system and then compared to the provincial and national health strategies of the DoH. A Consolidated Criterion for Reporting Qualitative research (COREQ) Checklist was applied to ensure all the requirements for qualitative research were met by this study.

\section{Ethical considerations}

Ethical clearance was received from the Biomedical Research and Ethics Committee at the University of KwaZulu-Natal 
(UKZN) (Ref: BE281/18). The study complied with the national research ethics guidelines and the UKZN policy on Research Ethics.

\section{Results}

A total of 28 optometrists responded to an invitation to participate in the study and completed the questionnaire survey. These 28 respondents were from 25 public health facilities, which makes up $60 \%$ of public health facilities that provide eye health care in KZN. The majority (53.6\%) of respondents were from district hospitals, with the remainder being from regional (25\%), tertiary $(3.6 \%)$, PHC $(7.1 \%)$ and community health centres $(10.7 \%)$.

Fifteen health facilities underwent the equipment audit. A 37\% response rate was received. Many (53\%) of the audited facilities were from rural areas, whilst $47 \%$ were from urban areas.

Five key informant interviews were conducted. Each of the interviewees were from different districts, two of which were coordinators within the $\mathrm{DoH}$, and three were hospital managers.

\section{Human resources for eye health}

\section{Demographics and placement of optometrists}

A total of $28(n=28)$ optometrists completed the questionnaire survey. Most participants were female $[57.1 \%(\mathrm{CI}=39.1 \%-$ $73.5 \%)]$, and between the ages of 26 and 35 [85.7\% (CI = $68.5 \%-94.3 \%)]$. The majority of the participants were black with a Bachelor optometry degree. Most of the optometrists from the questionnaire had less than 5 years' of experience [46.4\% (29.5\% - 64.2\%)]. At least one ophthalmic nurse was present in $77.0 \%$ of the facilities. The majority (53.6\%) of the respondents were based at district hospitals. Most facilities represented in the study were based in rural areas (75.0\%). Statistical and practical significance was found between the location of the facility and the level of care $(p=0.01$, Cramer's $V=0.6), C I=75 \%(55.1 \%-89.3 \%)$. Facilities which provided PHC (clinics and community health centres) were mainly found in rural areas, and those which provided secondary and tertiary care were found in urban and semi-urban areas.

\section{Recruitment and retention of optometrists}

The majority of optometrists $(75 \%)$ were employed within the public health sector because of contractual obligations linked to their undergraduate study bursaries. The rest of the respondents $(25 \%)$ were directly recruited through publicly advertised posts. Strong statistical evidence was found for gender $(p=0.01$, Phi $=0.5)$ and post-qualification experience $(p=0.01$, Cramer's $V=0.6)$ where most females who graduated in the previous 5 years were recruited into the public sector through the DoH health science bursaries. Although the relationship for the method of recruitment and facility level was found to be statistically insignificant $(p=$ 0.07 ), fairly strong practical evidence was found for this (Cramer's $V=0.6$ ). Most optometrists who were hired through the receipt of the health science bursary were hired in district hospitals.
Almost half of the participants (44.9\%) reported that they were actively seeking alternate employment. Only $10.3 \%$ of respondents felt that they were valued and motivated in their positions. Strong statistical and practical significance was found between levels of motivation and post qualification experience ( $p=0.04$, Cramer's $v=0.6)$, with those working for less than 5 years generally being demotivated.

\section{Available human resources}

When interviewees were questioned on the adequacy of HRs for primary eye care, a participant who is an official responsible for coordinating eye care services responded:

'My view is that we should look at the facilities and make sure that every CHC [Community Health Centre] and hospital at least has two optometrists each. So if you then look at it like that, I think we would need a little bit more.' (Participant 3, male, optometrist, eye health coordinator)

Only one questionnaire respondent reported a vacant post for an optometrist within their hospital. Ophthalmic support staff was available in most scenarios, primarily in the form of ophthalmic nurses, to support eye care service delivery within their health facilities.

\section{Roles, and responsibilities of optometrists}

Half (50\%) of the participants could not identify their employment ranking as either a junior or senior optometrist. Of the remaining participants, $40 \%$ were reportedly hired as junior optometrists and $10 \%$ were hired as senior optometrists. In a multiple response question probing into the core work the optometrists performed, approximately 93\% acted primarily in a clinical role, with $40 \%$ indicating they were required to perform administrative tasks as well.

\section{Decentralised clinical training programme and National Health Insurance}

When questioned about the Decentralised Clinical Training Programme (DCTP), optometrists felt that it would be a good initiative to better KZN's communities. Another optometrist commented that it would be a challenge if there is inadequate equipment. Concerning the National Health Insurance, all participants were optimistic about the commencement of this universal health coverage strategy. One participant commented that 'If NHI [National Health Insurance] is managed properly, we should have a positive impact. The issue of instruments will be taken care of and the issue of posts'. (Participant 7, male, Optometrist, uMgungundlovu district) This comment suggests that optometrists feel that the lack of equipment and HR negatively impacts primary eye health care service delivery.

\section{Service delivery and essential medicines}

\section{Nearest referral facility and wait times for an appointment}

The majority of optometrists $(82.1 \%)$ reported that the nearest referral facility required patients to travel long distances into 
urban areas. For the remainder, the nearest facility was typically within $30 \mathrm{~min}$ walking distance. In most instances, the typical waiting time to see an optometrist was the same day $(64.3 \%)$. At some facilities $(25 \%)$ patients could wait up to 3 weeks for an eye examination. Six months was the longest reported waiting period for a consultation with an optometrist. Observation by the researcher during the audit identified that wait times for patients varied according to the size and efficiency of the eye team within the clinics. On average, patients waited $2 h-4 h$ to be examined in the eye clinic, from the time the optometrist started a day's work.

\section{Services provided in KwaZulu-Natal facilities}

Refraction was performed at all sites (100.0\%), followed by diagnostics procedures (89.8\%) and vision screening (85.7\%). Most of the participants indicated that the reason for not providing certain services was the lack of equipment (69.4\%) and time constraints $(16.7 \%)(p=0.00)$.

\section{Provision of spectacles and essential medicines}

Less than a quarter of the facilities (22\%) provided spectacles for patients seen in the eye clinic. Of these, $73 \%$ outsourced their spectacle supply to private service providers. Almost half (46\%) of the facilities represented had a 1-month average waiting period for patients to receive spectacles after examination, with some waiting longer than a month. One participant commented that 'the main problem is that our spectacle delivery system is really weak'. (Participant 3, male, Optometrist, eye health coordinator) The survey results found that essential medicines that should be available at public eye clinics were reportedly provided following the list from the $\mathrm{DoH}(67 \%)$, were available at all times in the pharmacy $(62 \%)$, and were mostly free of charge to patients (57\%).

\section{Equipment and infrastructure}

In the questionnaire, optometrists were asked to comment on the state of equipment in the facility at which they were employed. Most respondents described the state of equipment available as either basic $(21.2 \%)$, or inadequate $(39.4 \%)$.
During an interview, one of the participants, an optometrist from the Amajuba district, commented that: '[ $h]$ aving equipment in hospitals, it's a slow process. The thing is, there are huge discrepancies - some hospitals are well equipped, and some don't have anything' (Participant 4, male, Optometrist, Amajuba district) when asked about the distribution of resources between facilities. Figure 2 shows the total required equipment available in eye health facilities in $K Z N$. As expected, tertiary hospitals have the highest amount of required equipment. Half (four of eight) of the district hospitals had less than $50 \%$ of the equipment required.

The facility checklist results show that most facilities that were audited were found only to have the basic equipment required for refraction, and therefore were inadequately equipped to provide comprehensive eye care services. This includes aspects such as binocular vision, paediatric assessments and contact lenses. Only 6 out of 15 facilities had visual field screening devices. Advanced imaging equipment (fundus camera and optical coherence topographer) was only found in two facilities, both of which were tertiary facilities located in urban areas. Functional vision tests, such as the Ishihara colour vision test, monocular estimate method (MEM) retinoscopy reading cards, and stereopsis tests; used in binocular vision, paediatrics, and low vision; were only available in hospitals which facilitate community based-training for undergraduate optometry students from the University of KwaZulu-Natal (UKZN).

\section{Health information systems for eye health}

The study sought out existing information systems in eye health through the interview process. Participants in the interview phase generally reported that there was not enough information available to guide the comprehensive planning of eye health services. The study sought out existing information systems in eye health through the interview process. Participants in the interview phase generally reported that there was not enough information available to

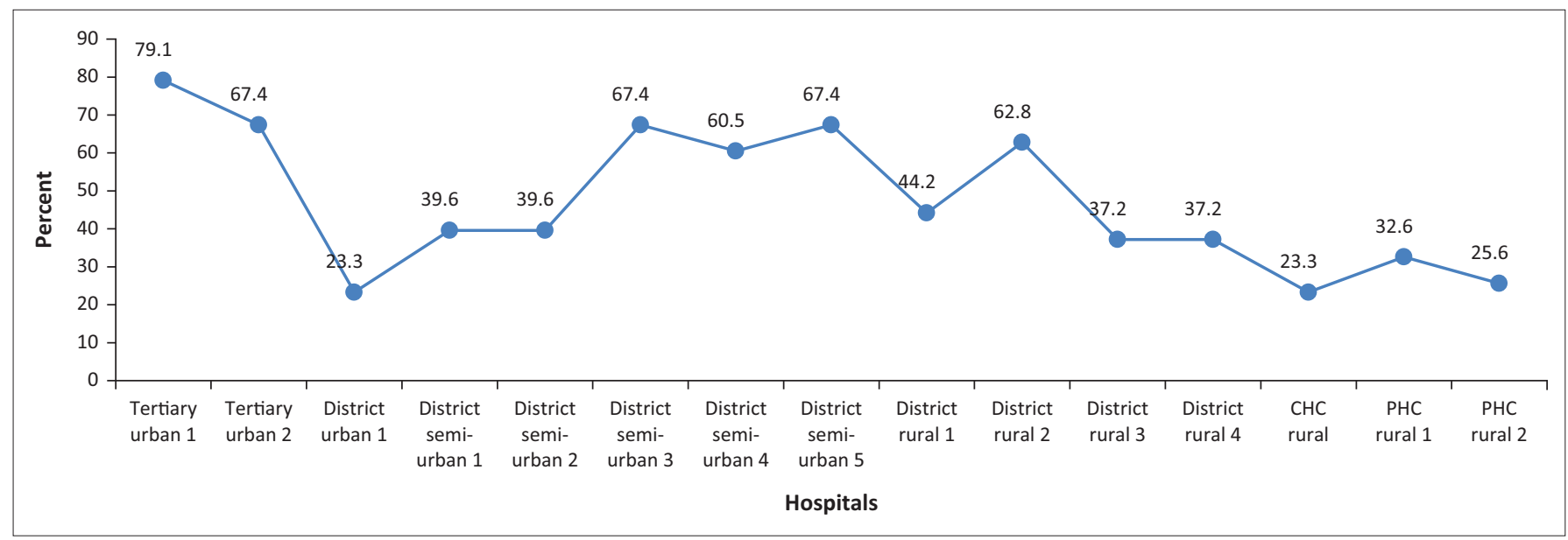

$\mathrm{CHC}$, community health centres; PHC, public health care.

FIGURE 2: Total available equipment in KwaZulu-Natal eye health facilities. 
guide the comprehensive planning of eye health services. One participant mentioning that:

‘[O]n an annual basis we have a performance plan, you may not find everything about eye health. For many years, we've always just had one element which is your Cataract surgery rate, so then everything that gets allocated around that.' (Participant 3, male, Optometrist, eye health coordinator)

He further discussed that eye health care fell under the broader category in non-communicable diseases (NCD) policies where eye health care governed.

\section{Finances for comprehensive eye health care in KwaZulu-Natal}

According to one of the interview participants, financing for eye care is not separate from the general health care funds as it does not have a dedicated budget. Consequently, funds for purchase and maintenance of equipment are therefore not available due to lack of budgets, or because of poor management of funds. Another key informant reported that the lack of funds for eye care services was the result of the prioritisation of other high morbidity health needs such as Tuberculosis and Human Immunodeficiency Virus / Acquired Immune Deficiency Syndrome. Regarding the filling of posts, health personnel such as medical doctors, nurses and dentists received priority. Consequently, eye health care is considered by health officials to not be an essential service, therefore it is not a priority when the budget is drafted. When asked about the major gaps in policy and resource distribution, a participant responded:

'I'd say it's prioritisation because when it comes to the issues of budgets and all of that, we [are] really struggling to the extent that there are things that are supposed to be done by other professionals for example nurses in clinics.' (Participant 1, male, Optometrist, uMzinyathi district)

This suggests that a lack of clear eye health policy results in certain tasks being performed by staff where these are not necessarily in their scope of practice or job function.

\section{Governance for comprehensive eye health care in KwaZulu-Natal}

Key informants reported that the DoH does not have a specific policy for delivering eye care to KZN. Eye health services are guided by broader national policies, and there is a sentiment that eye health has to make itself relevant to existing strategies as commented by a participant: 'Health is structured under different values because they have got broader government policies that we usually follow'. (Participant 3, male, Optometrist, eye health coordinator) According to another participant, there is currently an overstated focus on meeting the goals for cataract surgery rate but a vast majority of other gaps in the system are not addressed:

'The problem with those broader ones is that you may not explicitly find eye health. For many years, we've always just had one element which is your cataract surgery rate, so then everything gets allocated around that ... but you also locate it within the integrated development framework where you look at how eye health relates to all these NCD [Non-Communicable Disease] issues because it always has to be integrated otherwise you don't really get the support and resources. If yours is just a standalone, it does not relate.' (Participant 3, male, Optometrist, eye health coordinator)

\section{Discussion}

Gaps were evident in all components of the eye health system, and resources were found to be scarce and inequitably distributed. Equipment for comprehensive eye health service delivery was insufficient in most cases, with more advanced equipment located in urban areas.

Of concern is the finding that $45 \%$ of optometrists who participated in this study indicated their intent to leave the public service for employment opportunities elsewhere. This may lead to a loss of already scarce skills to the private sector or other professions, and further disadvantage eye health service provision for the majority of the KZN population who are dependent on the public health sector. However, it is not surprising in light of the finding that there is no clear career path for optometrists employed in the public health sector in KZN, and that optometrists generally feel undervalued as part of the health system. Employment rankings in the public service also determine the remuneration package for employees. The absence of clear guidelines for optometrists in this regard may also contribute to low levels of motivation. Therefore, structured job profiling and opportunities for promotion would likely support the retention of optometrists within the eye service in KZN. Upscaling infrastructure and improving the working environments are common themes in the solution to HR retention. ${ }^{27}$ The fact that many are not able to practise the full scope of optometry, and other systemic issues such as the inability to provide a reliable spectacle delivery system, may further contribute to levels of frustration amongst these eye health workers.

A well-functioning health system ensures quality, efficiency and cost-effectiveness through equitable access to essential medicines and equipment. ${ }^{28}$ Equipment is vital to quality service delivery and is closely linked to the motivation of eye care personnel to remain in the public health system. ${ }^{29}$ As essential equipment for comprehensive eye health service is either inadequate or unavailable in $\mathrm{KZN}$, and requests, for required or improved equipment and infrastructure, are not addressed, mainly the result of budget constraints, this may add to the level of disgruntlement amongst eye health staff. Advanced equipment only being found in urban areas shows the inequitable distribution of resources which results in patients having to travel long distances into urban areas, as reported by $83 \%$ of the respondents. Equitable access to pharmaceuticals and technologies must also be improved to strengthen KZN's ability to achieve its health goals. Whilst respondents in this study were aware of the list of available drugs and medicines for eye care, the reality is that in general, public sector facilities experience a high number of drug 
stock-outs ${ }^{30}$ which could result in inefficient delivery of basic eye care services. Equitable access to pharmaceuticals and technologies must, therefore, be improved to strengthen KZN's ability to achieve its health goals as this could negatively affect the treatment of patients who require medications for sight-threatening ocular diseases such as glaucoma. Mashige, ${ }^{31}$ Ramson $^{32}$ and Maake ${ }^{33}$ each found that there was a saturation of optometrists in urban areas, more so than in rural areas in KZN. Whilst these studies reported on the general distribution of optometrists considering both private and public sectors, the findings of this study are encouraging, as most respondents were located in rural areas; suggesting a deliberate effort by the KZN DoH to place more optometrists in marginalised communities, through the targeted health science bursary scheme, to reduce the burden of disease and provide accessible health care services. ${ }^{34}$ Increased accessibility of services in rural areas reduces the need for transportation costs imposed on patients to receive eye care in urban areas. However, the presence of public sector optometrists in urban and semi-urban areas remains necessary, to accommodate communities who may not be geographically excluded but are unable to afford private eye care services. Therefore, it is vital to ensure an adequate and proportionate distribution of HRs to meet eye health needs in both rural and urban communities of KZN.

Resourcing appears to be a challenge for the KZN DoH in terms of the scale and quality of eye health services provided. Currently, public sector optometrists offer basic eye care services that mainly include refraction, eye health assessment and vision screening. Limited binocular vision and pediatric services are offered, as well as ocular pathology diagnosis and management and basic low vision in some instances. This limits the ability of clinicians in the public health sector to provide comprehensive eye health services. Contact lenses are the least available eye health service, attributed largely to a lack of equipment. However, anecdotal evidence suggests that there is a high number of patients with keratoconus presenting to public sector facilities, where clinicians are illequipped to manage these cases, necessitating referral to the UKZN's eye clinic in Durban, in some cases more than $400 \mathrm{~km}$ away. Time constraints were also cited as a reason for not providing comprehensive services, which could be linked to the demand for service, added administrative responsibilities for optometrists and the logistical implications of patients' having to travel long distances to and from health facilities. The finding, that facilities supporting the clinical placement of university students were better equipped, is encouraging, indicating a potential partnership benefit within a service-learning model.

Increasing incentives, ${ }^{27}$ through improved salaries, promotion or capacity development opportunities, is amongst the top suggested HR retention strategy by the WHO. One contribution, which could lead to the improvement of the eye health service, is additional training and educational opportunities for clinical staff. Most respondents in this study indicated that they required supplementary training in management and leadership, as well as additional clinical refresher courses, suggesting their interest in advancement and promotion, as well as recognition of the need for formal training in non-clinical skills development. Anecdotal evidence suggests that there are currently no training courses provided by their employer, and most continuous professional development activities occur in urban areas. There is, therefore, a need for additional capacity development in outlying areas to support improvements in eye health service delivery. Health advocacy has also been identified as a core competency for health practitioners training, with a focus on health system development and transformative health professions education. ${ }^{35}$ Therefore, training in health advocacy may equip eye health staff with skills to drive necessary approaches towards improved service delivery.

The absence of policy, and a clear financing model for eye health, appears to impact the leadership and governance of eye health services, directly affecting service delivery. Many hospitals are not even able to provide a basic pair of spectacles to patients following an eye examination. Also, the compounding effect of poor planning appears to contribute to the recruitment and retention of optometrists in KZN. The absence of relevant evidence to support planning, therefore, affects decision-making at all levels, indicating that planning for eye health services requires a specific policy at government or provincial level, which could aid in building more sustainable, efficient and effective eye care services nationally. For eye health promotion to be successful, it requires more than document-based policy reforms, but needs widespread stakeholder support necessary to relay eye health needs through to funding and implementation. ${ }^{36}$ The NCD policy on the prevention of blindness mentions the goal of ensuring efficient and effective utilisation of resources. However, at the time of the study, there was no evidence of how the DoH would achieve this goal, as there was no recorded number of optometrists hired by the DoH, no official number of eye care facilities in KZN, no clear allocation of funding to eye health care in $\mathrm{KZN}$, and a lack of defined indicators for collection of health information systems (HIS) for eye health. If the DoH would aim the meet these goals, HIS would need to be developed to track the implementation and development of policy.

Information provided by literature and key informants places eye health care under the NCD policy in KZN. Unlike other health priorities, such as oral health and nutrition that have dedicated directorates, ocular health promotion is in the NCD, suggesting that it may not be a priority in the South African PHC system. It may be concluded that the lack of organised ocular health promotional structures, policies and activities is a consequence of a lack of a dedicated directorate for ocular health in KZN. According to the interviewees, only the cataract surgery rate (CSR) is recognised as an outcome that needs to be achieved.

With regards to a framework for integrated services for eye health, only one case of an Integrated school programme has 
been reported. There are 13 national health documents that were obtained in an eye health promotion in South Africa study in 2016. ${ }^{37}$ It found that only five of those documents contained goals for eye health care. Of those that did, the statements made were limited to only vision screening which usually only consists of visual acuity testing. This is problematic because vision screenings are largely ineffective because they rarely test for eye conditions that need to be diagnosed and treated such as cataracts, glaucoma and diabetic retinopathy, ${ }^{38}$ furthermore, over-referrals of patients who may not need attention, will put more pressure on the already strained eye health system. Nevertheless, Mahraj et al. ${ }^{39}$ conducted a vision screening study for primary schools in $\mathrm{KZN}$ and found that there is indeed a need for such a service, however, they experienced poor access to schools due to poor infrastructure, such as gravel roads. They concluded that there needs to be short, medium and longterm approaches to addressing service delivery needs and that a short-term programme would address a backlog of services to reach underserved school children. Other studies conducted on the effectiveness of VI screening in young children also revealed the need for more conclusive evidence about the efficacy and cost-effectiveness of preschool vision screening. ${ }^{38}$

The finding, that most public sector optometrists in KZN are young (under the age of 30 years), is considered both favourable and unfavourable. Young practitioners are generally inexperienced and, thus, present the possibility of ineffective patient management ${ }^{40}$ and underdeveloped expanded competencies such as management or leadership skills. Conversely, research suggests that as practitioners age, there is a decrease in performance. ${ }^{41}$ This could be because older practitioners generally show a lower adherence with up-to-date standards of care. ${ }^{41}$ Therefore, although skills and knowledge are accumulated through experience, which could improve the quality of care, scientific knowledge, technology, and clinical guidelines change regularly, and therefore younger practitioners would be more adaptable to the changing scope of practice and technological advances in optometric clinical practice. ${ }^{41}$ However, the DoH should try to ensure a wider age distribution and experience base of its clinical staff to balance the benefits that each category may offer. Gender distribution of respondents in this study was also consistent with the profile of undergraduate optometry students within the province of $\mathrm{KZN},{ }^{42}$ suggesting appropriate representation of practitioners in the system. The distribution of practitioner demographics also matches the dispersion of demographics of the KZN population, which is: $88.9 \%$ Black, $7.9 \%$ Indian, $2.3 \%$ White, and $0.9 \%$ Coloured. ${ }^{43}$ This is advantageous, as patients are more comfortable being treated and communicating with practitioners who are of the same language or ethnicity. ${ }^{44}$ This preference may arise as some patients prefer to speak their native language to communicate about certain topics. ${ }^{44}$ All clinicians should, however, have exposure and training in relevant competencies to deal with diverse patient groups. Training institutions would do well to consider methods of developing these skills in optometrists, to foster improved communication with people from different backgrounds, especially given the diversity of the South African and KZN contexts.

Currently, most optometrists in the public sector are unable to deliver services at the required level regarding their diagnostic scope of practice. The scope of practice for optometrists has further been increased to include therapeutic privileges, where practitioners undergo additional training. ${ }^{45}$ This includes the prescribing of drugs and medicines that treat a wider range of ocular diseases, which optometrists are already trained to assess and diagnose. ${ }^{45}$ In a study by Maake, $^{33}$ optometrists reported that more than $30 \%$ of referrals to ophthalmologists could be reduced if they were permitted to prescribe drugs to treat some ocular diseases. This expansion of scope is a form of task sharing strategy between optometrists and ophthalmologists, where optometrists treat basic ocular diseases to alleviate the burden on ophthalmologists, who are fewer in number than optometrists in the country. ${ }^{33}$ Available evidence identifies that, nationally, there are 262 optometrists in the public sector, which is more than twice that of ophthalmologists who are estimated at 113 practitioners in total. ${ }^{33}$ Task sharing has been recognised as one of the most important solutions to alleviate the HR crisis. ${ }^{27}$ However, maximising the clinical skills of optometrists will only be realised if facilities are adequately equipped for optometrists to function at the desired scope of practice level.

Tsugawa et al. ${ }^{40}$ identified that practitioners taking on supervisory roles results in fewer patients being seen. This was supported by evidence from some of the participants in this study. The assumption of additional responsibilities could, therefore, potentially impact service delivery. Long waiting times and delays in patient management could also potentially result from clinicians having to multitask. The optometrists in this study indicate that they desire capacity training in leadership and management, which suggests an acknowledged lack of skill to effectively and efficiently perform these roles. It is, therefore, disadvantageous to compound expectations from clinical staff whose primary role is to treat and manage patients. This would suggest the need for managerial positions where individuals are hired solely to perform administrative responsibilities.

Whilst optometrists in this study ranked, having access to decision-makers and key channels of enquiry, as an important intervention to aid in their retention, it is not clear what channels of enquiry exist, for optometrists to keep officials accountable for unmet goals, for the eye health service provision. Management and district officials must, therefore, open channels of engagement for these issues, and also be held accountable for the quality care in the areas they are designated to govern.

Globally, there is a lack of long-term investment in eye health care analysis and research to identify the marginalised 
populations, associated risk factors, cost-effective treatments, and an efficient public health system model to increase accessibility to eye health care for these populations. ${ }^{46}$ Evidence about the effectiveness of quality improvement interventions, where available, often reflects the health systems of higher-income countries that have the resources to implement and evaluate policy. Du Toit et al., ${ }^{17}$ in 2013, highlighted the need for integration of eye health into PHC in sub-Saharan Africa, which requires context-specific planning and a holistic approach with careful attention to each of the health system components and the public health system as a whole. Ho et al. ${ }^{47}$ also recently noted the lack of a comprehensive approach to guide priorities within eye care delivery where the appropriateness of eye care is measured. Dixon-Woods et al., ${ }^{48}$ however, suggested that there is no one solution to the improvement of quality service delivery, with the following as suggested solutions to health system strengthening:

- Dynamic adjustments of the building blocks, for example: incentivising clinician participation for improved service delivery.

- Integration of eye health services into PHC, where support from the general health system may assist in overcoming limitations and capabilities of the eye health care system.

- Transformative change to reduce the burden of disease, including assessing local systems, training people and having a quality assurance system in place. ${ }^{41}$

A limitation of this study is that it did not include contributions from ophthalmology or other ophthalmic staff within the public health sector in KZN. Despite this, clear gaps in the eye health service have been identified, underscoring the need for capacitating and strengthening the $\mathrm{KZN}$ DoH to improve eye health services in KZN. The interactions of these components must be managed in ways that achieve more equitable and sustainable health outcomes.

\section{Conclusion}

With all factors considered, the primary eye health service delivered by the KZN DoH appears to be weak, with the province having a limited capacity to provide comprehensive eye health care to its population. This is largely due to the current lack of integration of eye health into policy and planning. To strengthen the health system for comprehensive eye care service delivery, the KZN DoH must actively work towards developing appropriate policy that can support the eye health system as a whole, including service delivery, staff development and retention, and the ongoing capacity needs for eye health. This will ensure a sustainable eye health system which can provide comprehensive services through appropriate financing and resourcing, especially at PHC level, to reduce the burden of avoidable blindness and VI in KZN. Furthermore, there is a need for advocacy initiatives to educate both stakeholders and the public in terms of eye health services through public awareness campaigns on what constitutes comprehensive care, and the potential risks to population health and well-being if this need is not addressed. The KZN DoH must take advantage of the opportunities that the National Health Insurance and UKZN present in conjunction with the DCTP. This training model has the potential to alleviate HR constraints, improve service delivery, and offer accessible, affordable, and efficient primary eye care services.

\section{Acknowledgements Competing interests}

The authors declare that they have no financial or personal relationship(s) that may have inappropriately influenced them in writing this article.

\section{Authors' contributions}

Lungile Buthelezi conceptualised the project and Diane Van Staden contributed to project design, analysis and write up of the project. Both authors contributed to preparation of the manuscript.

\section{Funding information}

This research received no specific grant from any funding agency in the public, commercial, or not-for-profit sectors.

\section{Data availability statement}

Data sharing is not applicable to this article.

\section{Disclaimer}

The views and opinions expressed in this article are those of the authors and do not necessarily reflect the official policy of any affiliated agency of the authors.

\section{References}

1. World Health Organization. World Report on Vision [homepage on the Internet] Geneva; 2019. [cited 2019 Oct 21]. Available from: https://www.who.int/ publications-detail/world-report-on-vision

2. Bourne RRA, Flaxman SR, Braithwaite T, et al. Vision Loss Expert Group. Magnitude, temporal trends, and projections of the global prevalence of blindness and distance and near vision impairment: A systematic review and meta-analysis. Lancet Glob Health. 2017 Sept;5(9):e888-e897.

3. Fricke $\mathrm{T}$, Tahhan N, Resnikoff $\mathrm{S}$, et al. Global prevalence of presbyopia and vision impairment from uncorrected presbyopia. Ophthalmology [serial online]. 2018;125(10):1492-1499 [cited 2019 Dec 01]. Available from: https://www.ncbi. nlm.nih.gov/books/NBK402361/

4. Rius A, Lansingh, V, Valencia LG, Carter MJ, Eckert KA. Social inequalities in blindness and visual impairment: A review of social determinants. Ind Ophthalmol. 2012;60(5):368. https:doi.org/10.4103/0301-4738.100529

5. Sommer A, Taylor H, Ravilla $\mathrm{T}$, et al. Challenges of ophthalmic care in the developing world. JAMA Ophthalmol. 2014;132(5):640. https://doi.org/10.1001/ jamaophthalmol.2014.84

6. Javitt J, Venkataswamy G, Sommer A, Henkind P. The economic and social aspect of restoring sight. ACTA: 24th International Congress of Ophthalmology. New York: JP Lippincott; 1983, pp. 1308-1312.

7. Statistics South Africa. Public health care: How much per person?|Statistics South Africa [homepage on the Internet]. Statssa.gov.za; 2017 [cited 2019 Aug 17]. Available from: http://www.statssa.gov.za/?p=10548

8. Department of Health. Prevention of blindness in South Africa, South African Government. Directorate: Chronic Diseases, Disabilities and Geriatrics, Pretoria: National Department of Health; 2002.

9. Naidoo KS, Sweeney D, Jaggernath J, Holden B. A population-based study of visual impairment in the Lower Tugela health district in KZN, SA. Afr Vis Eye Health. 2013;72(3):a284. https://doi.org/10.4102/aveh.v72i3.284 
10. Govender P, Ramson P, Visser L, Naidoo K. Rapid assessment of avoidable blindness in The Northern Ethekwini District Of Kwazulu-Natal Province, South Africa. Afr Vis Eye Health. 2015;74(1):7. https://doi.org/10.4102/aveh. v74i1.15

11. World Health Organization. Universal eye health: A global action plan 2014-2019 [homepage on the Internet]. 2013 [cited 2019 Dec 03]. Available from: https:// www.who.int/blindness/actionplan/en/

12. Republic of South Africa Essential Drugs Programme. Primary health care standard treatment guidelines and essential medicines list. Pretoria: National Department of Health; 2014.

13. Lilian R, Railton J, Schaftenaar E, et al. Strengthening primary eye care in South Africa: An assessment of services and prospective evaluation of a health systems support package. PLoS One. 2018;13(5):e0197432. https://doi.org/10.1371/ journal.pone.0197432

14. Wright $H$, Turner A, Taylor H. Trachoma and poverty: Unnecessary blindness further disadvantages the poorest people in the poorest countries. Clin Exp Optometry. 2007;90(6):422-428. https://doi.org/10.1111/j.1444-0938.2007. 00218.x

15. Cook CD, Knight SE, Crofton-Briggs I. Prevalence and causes of low vision and blindness in northern KwaZulu. S Afr Med J. 1993;83(8):590-593.

16. Mariotti S, Rao G. Comprehensive eye care [homepage on the Internet]. 2019. [Cited 2019 Dec 01]. Available at: http://www.lionsclubs.org/resources/KO/pdfs/lcif/LCIF_ comprehensive_eye_care.pdf.

17. Du Toit $R$, Faal $H$, Etya'ale $D$, et al. Evidence for integrating eye health into primary health care in Africa: A health systems strengthening approach. BMC Health Serv Res. 2013;13(1):102. https://doi.org/10.1186/1472-6963-13-102

18. The world health report 2000: Health systems: Improving performance. Public Health Report. 2001;116(3):268-269. https://doi.org/10.1093/phr/116.3.268

19. Bryman A, Burgess R. Analyzing qualitative data. London: Routledge; 1999.

20. Anderson C. Presenting and evaluating qualitative research. Am J Pharm Educ. 2010;74(8):141. https://doi.org/10.5688/aj7408141

21. Statistics South Africa. KwaZulu-Natal citizens satisfaction survey: Analytical report, South African Government. Pretoria: StatsSA; 2018.

22. Lloyd B, Sanders D, Lehmann U. Human resource requirements for National Health Insurance. In: Padarath A, Fonn S, editors. South African Health Review 2010. Durban: Health Systems Trust, 2010, pp. 171-178.

23. Glen S. Purposive sampling (Deliberate sampling) - Statistics how to [homepage on the Internet]. Statistics How To; 2020 [cited 2020 Apr 05]. Available from: https://www.statisticshowto.com/purposive-sampling/

24. Who is an optometrist? - World Council of Optometry [homepage on the Internet]. Worldcouncilofoptometry.info; 2019 [cited 11 Sept 2019]. Available from: https://worldcouncilofoptometry.info/about-us/who-is-an-optometrist/

25. Health Professions Council of South Africa. Minimum equipment list [homepage on the Internet]. [cited 2018 Aug 20]. Available from: http://www.isystems.hpcsa. co.za>optometryminimum_equipment_list_1209

26. V2020eresource.org. VISION 2020 E-Resource [homepage on the Internet]. 2005 [cited 2019 Jan 13]. Available from: http://www.v2020eresource.org/home/ newsletter/news102005

27. Scheffler, R. and Tulenko, K. The deepening global health workforce crisis: Forecasting needs, shortages, and costs for the global strategy on human resources for health (2013-2030). Annals of Global Health. 2016, 82(3):510. https://doi.org/10.1016/j.aogh.2016.04.386

28. World Health Organization. Everybody's business - strengthening health systems to improve health outcomes: WHO's framework for action. Geneva, WHO press; 2007.

29. Patel D, Mercer E, Mason I. Ophthalmic equipment survey 2010: Preliminary results. Comm Eye Health. 2010;23(73):22-25.
30. Magadzire B, Budden A, Ward K, Jeffery R, Sanders D. Frontline health workers as brokers: Provider perceptions, experiences and mitigating strategies to improve access to essential medicines in South Africa. BMC Health Serv Res. 2014;14(1):520. https://doi.org/10.1186/s12913-014-0520-6

31. Mashige K, Oduntan O, Hansraj R. Opinions of South African optometry students about working in rural areas after graduation. Afr J Prim Health Care Fam Med. 2015;7(1):a799. https://doi.org/10.4102/phcfm.v7i1.799

32. Ramson P, Govender P, Naidoo K. Recruitment and retention strategies for public sector optometrists in KwaZulu-Natal Province, South Africa. Afr Vis Eye Health. 2016;75(1):a349. https://doi.org/10.4102/aveh.v75i1.349

33. Maake M, Moodley V. An evaluation of the public sector optometric service provided within the health districts in KwaZulu-Natal, South Africa. Afr Vis Eye Health. 2018;77(1):a407. https://doi.org/10.4102/aveh.v77i1.407

34. KwaZulu-Natal Department of Health Bursary SA 2019-2020 [homepage on the Internet]. Zabursaries.co.za; 2019 [cited 12 Sept 2019]. Available from: http:// www.zabursaries.co.za/government-bursaries-south-africa/kzn-department-ofhealth-bursary/

35. Gaede B, Pillay P. Advocacy: Are we teaching it? Afr J Health Prof Educ. 2019;11(2):63. https://doi.org/10.7196/AJHPE.2019.v11i2.1042

36. Singh S. A critical analysis of the provision for oral health promotion in South African Health Policy Development [Doctor of Philosophy (Dental Public Health) Thesis], 2005.

37. Sithole H. A situational analysis of ocular health promotion in the South African primary health-care system. Clin Exp Optometry. 2016;100(2):167-173. https:// doi.org/10.1111/cxo.12452

38. Unite for sight. Challenges and failures of vision screenings [homepage on the Internet]. 2015 [cited 2020 Apr 09]. Available from: https://www.uniteforsight. org/health-screenings/vision-screenings

39. Mahraj Y, Naidoo K, Dabideen R, Ramson P. The KwaZulu-Natal Child Eye Care Programme: Delivering refractive error services to primary school learners. Afr Vis Eye Health. 2011;70(2):a100. https://doi.org/10.4102/aveh.v70i2.100

40. Tsugawa Y, Newhouse J, Zaslavsky A, Blumenthal D, Jena A. Physician age and outcomes in elderly patients in hospital in the US: Observational study. BMJ. 2017;357:j1797.

41. Choudhry N, Fletcher R, Soumerai S. Systematic review: The relationship between clinical experience and quality of health care. Ann Intern Med. 2005;142(4):260, 60-73. https://doi.org/10.7326/0003-4819-142-4-200502150-00008

42. Nirghin U, Khan N, Mashige K. Institutional, gender and racial profiles of South African optometrists. Afr Vis Eye Health. 2011;70(3);a107. https://doi. org/10.4102/aveh.v70i3.107

43. Statistics South Africa. General Household Survey. Pretoria: StatsSA; 2019.

44. Nwabueze C, Nwankwo N. Ethnicity and doctor-patient communication: An exploratory study of University of Abuja Teaching Hospital, Nigeria. J Participat Med. 2016;8:e12

45. SA Optometrists seal legislation for ocular therapeutics [homepage on the Internet]. Eye Zone; 2016 [cited 15 Jul 2019]. Available from: http://eyezonemag. $\mathrm{com} / \mathrm{blog} / 2016 / 06 / 21 / \mathrm{sa}$-optometrists-seal-legislation-for-ocular-therapeutics/

46. Welp A, Woodbury RB, McCoy MA, et al., editors. Making eye health a population health imperative: Vision for tomorrow. Washington, DC: National Academies Press (US); 2016

47. Ho K, Stapleton F, Wiles L, et al. Systematic review of the appropriateness of eye care delivery in eye care practice. BMC Health Serv Res. 2019;19(1):646. https:// doi.org/10.1186/s12913-019-4493-3

48. Dixon-Woods M, McNicol S, Martin G. Ten challenges in improving quality in health care: Lessons from the Health Foundation's programme evaluations and health care: Lessons from the Health Foundation's programme evaluations and relevant literature: Table 1 . BMJ
org/10.1136/bmjqs-2011-000760 